\title{
A Study of the Electrochemical Performance of Strip Supercapacitors under Static and Dynamic Mechanical Tests
}

\author{
Ruirong Zhang ${ }^{*}$, Yanmeng Xu*, David Harrison and John Fyson \\ Cleaner Electronics Group, College of Engineering, Design and Physical Sciences, Brunel University \\ London, Uxbridge, UK \\ *E-mail: ruirong.zhang@brunel.ac.uk, yanmeng.xu@brunel.ac.uk
}

doi: $10.20964 / 2017.02 .53$

Received: 1 September 2016 / Accepted: 20 December 2016 / Published: 30 December 2016

\begin{abstract}
Flexible and stretchable supercapacitors have a big potential of being used in portable and wearable electronics because of their high power density, high reversibility, fast charge/discharge rates and long life cycles. In this study, strip supercapacitors were fabricated by a blade coating process using lowcost materials. The electrochemical performance of the strip supercapacitors was studied under both static and dynamic tensile stress conditions in order to evaluate their suitability for use in wearable textiles. The results showed strip supercapacitors under static and dynamic mechanical tensile process worked well: the capacitance and specific capacitance for this strip supercapacitor sample with the static loading of $100 \mathrm{~N}$ or $200 \mathrm{~N}$ was bigger than that of this sample without loading, with an increase of $22 \%$ and $9 \%$, respectively. The mechanical compression was applied vertically from the top of the strip supercapacitor sample to further investigate the reason for the capacitance increase under loading conditions.
\end{abstract}

Keywords: Flexible supercapacitors - Static and dynamic mechanical test - Mechanical pressure $\cdot$ Electrochemical performance

\section{$\underline{\text { FULL TEXT }}$}

(C) 2017 The Authors. Published by ESG (www.electrochemsci.org). This article is an open access article distributed under the terms and conditions of the Creative Commons Attribution license (http://creativecommons.org/licenses/by/4.0/). 